\title{
Jurisprudentie
}

\section{Rechtszekerheid en redelijkheid en billijkheid in het erfrecht}

\section{Een verhandeling naar aanleiding van Hof Den Haag 12 mei 2020}

\author{
Mr. T.F.H. Reijnen*
}

\section{Introductie}

De casus van de uitspraak van hof Den Haag van 12 mei 2020, ECLI:NL:GHDHA:2020:891, acht ik bekend: de strijd ging over de nalatenschap van een in de Dominicaanse Republiek overleden vrouw. Op huwelijksreis zijn de man en de vrouw kort na elkaar overleden. Hoewel grote onduidelijkheid bestaat over het tijdstip van overlijden, is zowel de rechtbank als het hof van oordeel dat de vrouw enkele minuten voor de man is overleden. De vraag was wie tot de nalatenschap van de vrouw is gerechtigd. Rechtbank Den Haag oordeelde dat hoewel de vrouw eerder is overleden dan de man, op grond van de redelijkheid en billijkheid de nalatenschap van de vrouw werd verkregen door haar familie en de nalatenschap van de man door zijn familie. De moeder van de man laat het hierbij niet zitten en gaat tegen het vonnis van de rechtbank in hoger beroep bij het gerechtshof Den Haag. In hoger beroep vernietigt het hof de uitspraak van rechtbank Den Haag. Het hof oordeelt dat in het erfrecht plaats is voor de redelijkheid en billijkheid uit artikel 6:2 van het Burgerlijk Wetboek $(\mathrm{BW})$, maar dat in deze casus geen grond anwezig was om af te wijken van artikel 4:10 BW. De omstandigheden van het geval waren niet zo uitzonderlijk dat de wet plaats moet maken voor de toepassing van de rede- lijkheid en billijkheid, mede vanwege het grote belang dat het hof hecht aan de rechtszekerheid in het erfrecht. In het navolgende zal ik ingaan op de rechtszekerheid in het erfrecht. Daarnaast bespreek ik de afwegingen van het hof ten aanzien van de redelijkheid en billijkheid. Mijn conclusie zal zijn dat de rechtszekerheid in het erfrecht belangrijk is, maar niet groter dan in andere rechtsgebieden. Hieruit vloeit als vanzelf voort dat het rechtszekerheidsargument van het hof niet valide is. Ten aanzien van de redelijkheid en billijkheid trek ik dezelfde conclusie als eerder de rechtbank deed.

\section{Rechtszekerheid volgens het hof}

Een overweging uit het arrest van het hof waarover ik mijn bedenkingen heb, is de volgende:

'Een belangrijk rechtsbeginsel in het erfrecht is dan ook het beginsel van rechtszekerheid, in de zin van zekerheid over wat de regels inhouden in een specifieke situatie.'

Ik begrijp deze zin niet als het hof bedoelt dat wanneer de algemene rechtsregels bekend zijn, het antwoord in een concrete casus kan worden gegeven. Een jurist kent de rechtsregels slechts uit de feiten, of zoals Schoordijk schreef: 
'Ook een rechter die grondig geschoold is en/of jarenlang gedoceerd heeft, de wet met nummer en al kent, kan als hem een rechtsvraag voorgelegd wordt, veelal niet direct oordelen zonder het dossier of inlichtingen te vragen.'

Volgens mij is de redelijkheid en billijkheid een belangrijke reden hiervoor. De redelijkheid en billijkheid mag wat mij betreft gerekend worden tot een van de kernwaarden van ons recht en is alleen al daarom ook van toepassing op het erfrecht. In de wet komt dat het meest algemeen tot uitdrukking in artikel 6:2 BW. De te kennen regels omvatten dus niet alleen de commoriëntenregeling van artikel 4:2 BW en de gevolgen daarvan voor de toepassing van artikel 4:10 BW, maar ook de regels van de redelijkheid en billijkheid. Voordat de regel in een specifieke casus gekend kan worden, zullen de feiten in het licht van de rechtsregels, waaronder de redelijkheid en billijkheid, beoordeeld moeten worden. Dat kan niet altijd met de zekerheid waar het hof naar verlangt. En dat is ook niet erg.

\section{Helderheid op korte termijn}

Naast de rechtszekerheid legt het hof tevens nadruk op de belangen van derden die bij het erfrecht in het geding zijn. De regel uit artikel 4:2 BW is in de wet opgenomen, zodat op korte termijn kan worden vastgesteld wie tot de nalatenschap is gerechtigd. ${ }^{3}$ De vraag is echter: is snelheid van belang? Snelheid is niet van belang, is mijn antwoord. Dat ook de wetgever niet uitgaat van snelle en eenvoudige vaststelling van wie tot een nalatenschap gerechtigd is, blijkt uit tal van bepalingen. Hierna ga ik nader in op het tijdsargument en op het argument van de rechtszekerheid voor erfgenamen en derden.

\subsection{Helderheid op korte termijn over de vraag wie erfgenaam is}

Het hof merkt terecht op dat de man en de vrouw al op 12 juni 2016 zijn overleden en dat bij het wijzen van het arrest nog steeds niet vaststaat wie erfgenamen van de vrouw zijn. ${ }^{4}$ Dit is op zichzelf een juiste weergave van de feiten, maar kan op geen enkele wijze dienen als argument voor de uitspraak van het hof. De reden dat nog niet vaststaat wie de erfgenamen zijn, heeft niets van doen met kennelijk lichtvaardig procederen. Immers, de rechtbank heeft de familie van de vrouw in het gelijk gesteld en geoordeeld dat de nalatenschap van de vrouw hun toekomt. Ook hof Den Haag heeft eerder in 2018 al geoordeeld dat de tijdspanne tussen het overlijden van de ene echtgenoot en de andere echtgenoot dermate kort was dat de vraag kan worden gesteld of onverkorte aansluiting bij het wettelijk erfrecht in dezen passend is. ${ }^{5}$ In zijn uitspraak van 12 mei 2020 oordeelt hof Den Haag dat de man enig erfgenaam was van de vrouw, zodat de nalatenschappen van zowel de man als de vrouw aan de erfgenamen van de man toekomen. Zo vanzelfsprekend is het antwoord op de vraag wie de erfgenamen van de vrouw zijn dus niet. En wie weet wat de uitkomst is van een eventuele cassatieprocedure.

Snelle duidelijkheid over wie erfgenaam is, is ook geen uitgangspunt van het Nederlandse erfrecht. De wet eist niet dat een erfgenaam eenvoudig te traceren is. De enige eisen die de wet stelt aan een wettelijk erfgenaam is dat deze bestaat ten tijde van het openvallen van de nalatenschap (art. 4:56 BW). Als bij uiterste wil over de nalatenschap wordt beschikt, komt daar nog de eis bij van directe identificeerbaarheid (art. 4:115 BW). Deze eis wil niet zeggen dat het direct duidelijk moet zijn wie erfgenaam is, maar dat uit de uiterste wilsbeschikking en de op het ogenblik van het overlijden van de erflater bestaande omstandigheden af te leiden is wie de erfgenaam is. ${ }^{6} \mathrm{Zo}$ wordt voldaan aan de eis van directe identificeerbaarheid als de laatste Nederlandse schaatskampioen op de 10 kilometer tot erfgenaam is benoemd, maar niet als de komende kampioen tot erfgenaam is benoemd.

De praktijk leert dat het heel lang kan duren alvorens alle erfgenamen zijn opgespoord. Velen die ervaring hebben in de notariële boedelpraktijk kennen het fenomeen van 'dossiervererving'. In sommige nalatenschappen is het zo lastig de erfgenamen op te sporen, dat dossiers van kandidaat-notaris op kandidaat-notaris worden overgedragen. De afwikkeling kan jaren, soms tientallen jaren op zich laten wachten. Toch is er niemand die zal beweren dat alleen erfgenamen die op korte termijn opgespoord worden, tot de nalatenschap gerechtigd zijn. Ook kan het zijn dat men overtuigd is dat alle erfgenamen bekend zijn, maar later nog een erfgenaam op het toneel verschijnt door de gerechtelijke vaststelling van het ouderschap op basis van artikel 1:207 BW. De gerechtelijke vaststelling van het ouderschap werkt terug tot de geboorte van het kind. Daarom kan het gebeuren dat nog een kind tot de nalatenschap gerechtigd is, dat voorheen niet als erfgenaam in beeld was. ${ }^{7}$

Het argument van de korte termijn waarbinnen kennelijk volgens het hof duidelijkheid moet bestaan over de vraag op wie de goederen van de nalatenschap overgaan, heeft geen basis in het recht. Ook hoeft men niet bang te zijn voor 'zwevend vermogen'. Het wettelijk systeem zorgt ervoor dat altijd iemand tot de nalatenschap van een erflater gerechtigd is en wel vanaf de dag
2. H.C.F. Schoordijk, Realistische en pragmatische rechtsvinding. Taak en taakopvatting van de rechter in de westerse wereld, Oisterwijk: Wolf Legal Publishers 2014, p. 153. Vgl. ook Asser/Vranken Algemeen deel $^{* *}$ 1995/85. Vranken schrijft dat als de norm duidelijk is, de toepassing daarvan in de concrete omstandigheden van het geval nog niet eenvoudig is vanwege de redelijkheid en billijkheid.

3. R.o. $4.8,4.9$ en 4.11 .

4. R.o. 4.11 .
5. Geciteerd in Rb. Den Haag 16 januari 2019, ECLI:NL:RBDHA:2019:4, RN 2019/27, r.o. 2.9.

6. Zie hierover N.V.C.E. Bauduin, Wilsdelegatie in het erfrecht (diss. Nijmegen), Deventer: Kluwer 2014, par. II.5.2.2.

7. M.J.A. van Mourik, in: Handboek Erfrecht, Deventer: Wolters Kluwer 2020, par. III.1. 
van overlijden. ${ }^{8}$ Dat het enige tijd duurt voordat wij weten wie dat is, doet daar niet aan af.

\subsection{Derdenbescherming}

Wellicht is men geneigd het hof gelijk te geven in zijn oordeel dat derden moeten weten waar zij aan toe zijn, bijvoorbeeld kopers van een in de nalatenschap vallende woning. ${ }^{9}$ Hoe zit het eigenlijk met derdenbescherming en een nalatenschap? Ik laat een aantal derdenbeschermingsbepalingen en bepalingen die kunnen leiden tot derdenbescherming de revue passeren. ${ }^{10}$

\section{- $\quad$ Artikel 1:207 lid 5 BW}

Artikel 1:207 BW, dat de gerechtelijke vaststelling van het ouderschap regelt, kent in lid 5 een beschermingsbepaling. Dit is nodig omdat de gerechtelijke vaststelling van het ouderschap terugwerkt tot de geboorte van het kind. Artikel 1:207 lid 5 BW voorkomt dat te goeder trouw door derden verkregen rechten worden geschaad. Een voorbeeld. Als tot een nalatenschap een pakket aandelen in A BV behoort en de drie bekende kinderen van de erflater dragen deze aandelen krachtens koop over aan een derde, dan is die derde gerechtigd geworden tot de aandelen. Ook als na een gerechtelijke vaststelling van het ouderschap blijkt dat vier kinderen tot de nalatenschap gerechtigd zijn. Ondanks dat niet alle gerechtigden meegewerkt hebben aan de overdracht, geldt de koper als enig gerechtigde tot de aandelen.

Degene die erfgenamen zouden zijn als geen gerechtelijke vaststelling van het ouderschap zou hebben plaatsgevonden, zijn geen derden in de zin van artikel 1:207 lid 5 BW. ${ }^{11}$

- $\quad$ Artikel 3:17 lid 1 sub e $B W^{12}$

Een uitvoerbaar bij voorraad verklaarde declaratoire uitspraak van de rechter kan worden ingeschreven in de openbare registers. ${ }^{13}$ Zo ook het vonnis van rechtbank Den Haag van 16 januari 2019, dat ten grondslag ligt aan de uitspraak van hof Den Haag van 12 mei 2020. Een derde die de tot de nalatenschap behorende woning wil verkrijgen van de erfgenamen, weet hierdoor dat onduidelijkheid bestaat ten aanzien van de gerechtigdheid tot de woning, in elk geval totdat de rechterlijke uitspraak in kracht van gewijsde is gegaan.

8. Dit kan een wettelijke erfgenaam zijn of een benoemde erfgenaam Ingeval er geen erfgenaam is, is de Staat vanaf het openvallen van de nalatenschap daartoe gerechtigd (art. 4:189 BW). Zie ook Bauduin, Wilsdelegatie in het erfrecht, par. II.5.2.2.4

9. R.0. 4.7

10. $\mathrm{k}$ heb niet de pretentie volledig te zijn, er zullen ongetwijfeld nog andere beschermingsbepalingen bestaan die ik niet behandel. Voor beschermingsbepalingen in het erfrecht zie ook L.C.A. Verstappen, in: Handboek Erfrecht, Deventer: Wolters Kluwer 2020, par. XIII.6.6.

11. Hof Amsterdam 26 februari 2019, ECLI:NL:GHAMS:2019:622.

12. Zie over art. 3:17 BW G.T. de Jong, De eis van inschrijving van een rechtsmiddel tegen rechterlijke uitspraken betreffende registergoederen in het rechtsmiddelenregister: een kritische benadering, NTBR 2009/7.

13. MvT, Parl. Gesch. Boek 3, p. 117.

14. Zie over art. 3:24 BW A.A. van Velten, Privaatrechtelijke aspecten van onroerend goed (Ars Notariatus nr. 120), Deventer: Wolters Kluwer 2018/6.6.1.

\section{- $\quad$ Artikel 3:24 lid 3 BW $W^{14}$}

De verkrijger onder bijzondere titel geniet grote bescherming tegen de onvolledigheid van de openbare registers (art. 3:24 lid $1 \mathrm{BW}$ ). De bescherming geldt ook als wordt verkregen van de erfgenamen, zij het met een beperking. Pas na drie maanden mag een verkrijger erop vertrouwen dat de ingeschreven gerechtigden ook daadwerkelijk de erfgenamen zijn (art. 3:24 lid 3 BW). ${ }^{15}$ De reden hiervoor is dat het soms lang kan duren voordat de erfgenamen of uiterste wilsbeschikkingen worden achterhaald. ${ }^{16}$ Een voorbeeld. De weduwe van A verkoopt twee maanden na diens overlijden de (voormalige) echtelijke woning aan $\mathrm{X}$. In de openbare registers is een door de notaris opgemaakte verklaring van erfrecht ingeschreven waaruit blijkt dat de weduwe enig erfgenaam is van $\mathrm{A}$. Na de levering van de woning blijkt dat $\mathrm{A}$ in het buitenland een uiterste wilsbeschikking heeft gemaakt, waarbij hij zijn echtgenote heeft uitgesloten als erfgenaam. Als die uiterste wilsbeschikking binnen drie maanden na het overlijden van A wordt ingeschreven, geniet $\mathrm{X}$ geen bescherming. Wordt de uiterste wilsbeschikking pas ingeschreven nadat drie maanden na het overlijden zijn verstreken, dan is $\mathrm{X}$ wel eigenaar geworden.

Opgemerkt dient te worden dat voor vorderingen op naam en aandelen op naam in een vennootschap geen met artikel 3:24 BW te vergelijken bepaling bestaat. ${ }^{17}$

\section{- Artikel 3:86 BW}

Artikel 3:86 BW bevat een bescherming van de verkrijger van roerende zaken, rechten aan toonder en rechten aan order tegen beschikkingsonbevoegdheid van de vervreemder. De bescherming geldt alleen bij verkrijgingen om baat en als de verkrijger te goeder trouw is. Bij verkrijging uit een nalatenschap is artikel 3:86 BW ook van toepassing. De verkrijger wordt beschermd tegen beschikkingsonbevoegdheid van degenen die zich presenteren als de erfgenamen, als aan de overige voorwaarden (om baat, te goeder trouw) is voldaan. Dat later een of meer anderen (mede) tot de nalatenschap gerechtigd zijn, doet aan de verkregen rechten van de verkrijger niet af.

De verkrijger van vorderingsrechten kan geen bescherming ontlenen aan artikel 3:86 BW.

- $\quad$ Artikel 4:191 lid 2 BW

In een geval waarin het traceren van de erfgenamen lastig en tijdrovend was, heeft de kantonrechter aan een derde het tijdelijk beheer opgedragen van de nalatenschap van erflaatster. ${ }^{18}$ Wat kennelijk meespeelde in de beslissing was dat de nalatenschap positief was en de procedure goedkoper dan die van een vereffening. De

15. Erfopvolging is inschrijfbaar op grond van art. 3:17 lid 1 sub b BW.

16. Parl. Gesch. Boek 3, p. 136.

17. Zie ten aanzien van aandelen S. Perrick, Een verdergaande bescherming tegen beschikkingsonbevoegdheid over aandelen op naam, Ondernemingsrecht 2019/16.

18. Rb. Midden-Nederland 21 september 2017, ECLI:NL:RBMNE: 2017:4852, JERF 2017/296, waarover H.J. de Jonge, Een vlotte(re) boedelafwikkeling via de weg van artikel 4:191 lid 2 BW, JBN 2018/48. 
benoeming van een beheerder op de voet van artikel 4:191 lid 2 BW werkt op deze wijze als bescherming van derden-schuldeisers.

\section{- Artikel 6:34 BW}

Als achteraf blijkt dat anderen tot de nalatenschap zijn gerechtigd dan voordien werd gedacht, hoeft een schuldenaar van de erflater niet voor de tweede keer te betalen. Artikel 6:34 BW bepaalt dat een schuldenaar in een dergelijk geval bevrijdend heeft betaald. De voorwaarden zijn dat hij op redelijke gronden heeft aangenomen dat hij aan de gerechtigde heeft betaald. Dat is bijvoorbeeld het geval als de schuldenaar een verklaring van erfrecht wordt overlegd waaruit blijkt wie de erfgenamen zijn. Ook als later blijkt dat de verklaring van erfrecht onjuist is (art. 4:187 lid 4 BW).

\section{- Samenloop van beschermingsbepalingen}

Verstappen merkt op dat als een derde een beroep kan doen op meer dan één beschermingsbepaling, hij keuzevrijheid heeft. Een derde hoeft zich daarbij niet te beperken tot één enkele grondslag. ${ }^{19}$

\section{De notaris en de verklaring van erfrecht}

De gedachte kan opkomen dat het voor een notaris onmogelijk is een verklaring van erfrecht op te maken als artikel 4:10 BW geen 'fast and hard rule' is. Ten onrechte, in principe geldt artikel 4:10 BW. Als de notaris met voldoende zekerheid kan vaststellen wie als eerste is overleden, kan hij de verklaring van erfrecht opmaken waarin degenen die op grond van artikel 4:10 BW tot de nalatenschap gerechtigd zijn, als erfgenamen worden aangewezen. ${ }^{20}$ De redelijkheid en billijkheid komt immers pas om de hoek kijken zodra gesteld wordt dat van een wettelijke regel moet worden afgeweken. Het is daarmee aan degene die meent dat de regeling niet toegepast moet worden, dat in rechte aan te tonen. ${ }^{21}$ Zolang dat niet gebeurt, geldt de wettelijke regeling onverkort. Derden die vertrouwen op de verklaring van erfrecht worden zo veel mogelijk beschermd (art. 4:187 lid $1 \mathrm{BW})$. Dat inschrijving van de verklaring van erfrecht in de openbare registers hierbij een must is als tot de nalatenschap registergoederen behoren, is hiervoor bij de behandeling van artikel 3:24 BW al an bod geweest. Als de notaris 'er lucht van heeft gekregen' dat een of meer personen menen rechten te hebben die voortvloeien uit de wet, zou de notaris kunnen overwegen hun een termijn te stellen waarbinnen zij zich moe-

19. Verstappen, Handboek Erfrecht, par. XIII.7.

20. Opgemerkt kan worden dat in de casus van hof Den Haag van 12 mei 2020 duidelijk is geworden dat ook als een overlijdensakte is opgemaakt, het tijdstip van overlijden allesbehalve vast is.

21. Onder omstandigheden zal ook een vaststellingsovereenkomst gesloten kunnen worden waarbij vastgesteld wordt dat de wettelijke regeling niet toegepast dient te worden vanwege de redelijkheid en billijkheid en partijen overeenkomen wat de gevolgen daarvan zijn. ten uitspreken. ${ }^{22}$ Een situatie als die uit Hof Amsterdam 26 februari 2019, ECLI:NL:GHAMS:2019:622, moet zo veel mogelijk worden voorkomen. In de casus van deze uitspraak ging het om een broer van de erflater die een notaris een verklaring van erfrecht had laten opmaken. Eerder hadden twee andere notarissen dat geweigerd omdat twee biologische kinderen wellicht een procedure uit artikel 1:207 BW zouden instellen. Tegen de derde notaris had de broer zijn mond hierover gehouden. Maar wat kan een notaris met de mededeling dat er 'wellicht nog biologische kinderen zijn'? Zolang het ouderschap van de erflater niet overeenkomstig artikel 1:207 BW is vastgesteld, zijn zij geen erfgenaam. De notaris kan dan ook niet anders dan een verklaring van erfrecht opmaken waaruit het erfgenaamschap op dat moment blijkt. Als de biologische kinderen uit de casus niet hadden gewild dat de oom zich als erfgenaam gedroeg, hadden zij de kantonrechter kunnen verzoeken een beheerder van de nalatenschap aan te stellen. ${ }^{23}$ Zowel het verzoek tot gerechtelijke vaststelling ouderschap als het verzoekschrift tot benoeming van een beheerder kan volgens mij op grond van artikel 3:17 lid 1 sub $\mathrm{f} \mathrm{BW}$ worden ingeschreven in de openbare registers. Op deze wijze weten (ook) derden waar zij aan toe zijn, zonder dat de potentiële erfgenaam (zoals de familie van de vrouw in de zaak die speelde voor hof Den Haag of de biologische kinderen in de casus van hof Amsterdam) de erfgenamen volgens de conventionele regels kan gijzelen. Die gijzeling is mogelijk omdat zij lang kunnen talmen met het instellen van een vordering. Rechtsverwerking zal op een gegeven moment haar werk doen, maar niet bij ouderschapsvaststellingsacties.

\section{Het systeem van de wet}

In r.o. 4.8 e.v. gaat het hof in op de parlementaire geschiedenis van artikel 878 lid $1 \mathrm{BW}$ (oud) en zijn opvolger, artikel 4:2 BW. Deze laatste bepaling is op haar beurt mede gebaseerd op de Benelux-Overeenkomst inzake commorientes die Nederland in 1972 met België en Luxemburg heeft gesloten. Uit de in r.o. 4.8 geciteerde passage uit de memorie van toelichting bij de goedkeuringswet blijkt welke motieven ten grondslag hebben gelegen te kiezen voor het systeem opgenomen in artikel 4:2 BW:

'In de eerste plaats is iedere termijn binnen de welke de personen zouden moeten zijn overleden, om het wettelijk vermoeden te laten gelden, willekeurig. In de tweede plaats zou het criterium "eenzelfde gebeurtenis" tot uiteenlopende interpretaties aanleiding

22. Dit mag volgens mij alleen met toestemming van degenen die erfgenamen zijn als de procedure tot vaststelling van het ouderschap niet wordt ingesteld, Hof Amsterdam 23 januari 2018, ECLI:NL:GHAMS:2018:166. Als de notaris geen toestemming krijgt tot het stellen van een termijn, zal hij naar mijn mening een verklaring van erfrecht moeten afgeven. De feiten liggen dan immers zoals zij liggen. Het is dan aan de belanghebbenden bij de procedure hun recht te halen.

23. Zie hiervoor art. 4:191 lid 2 BW. 
kunnen geven. En in de laatste en voornaamste plaats lijkt het niet gewenst een rechtsvermoeden op te nemen dat duidelijk in strijd is met de werkelijkheid. ${ }^{24}$

In dat kader acht de minister het niet bezwaarlijk dat het spoedig na elkaar overlijden tot een toevallige uitkomst kan leiden. ${ }^{25}$

Vervolgens komt het hof met argumenten waarom volgens hem in de voorliggende casus geen reden bestaat op grond van de redelijkheid en billijkheid van de wet af te wijken. De gevolgen van de vermogensovergang zijn niet zodanig dat dit naar de maatstaven van de redelijkheid en billijkheid onaanvaardbaar is.

Op zichzelf kan ook ik goed uit de voeten met de wettelijke regeling. Waar het bij mij knaagt, is als bij de 'gebeurtenis' derden betrokken zijn, zoals medici. De vraag is dan: is de volgorde van overlijden beïnvloed door het (medisch) handelen? Het nog een paar minuten langer reanimeren van een van beiden kan bepalen naar welke familie het vermogen gaat. Die gevolgen mogen niet afhankelijk zijn van het werk van hulpverleners.

In dat kader heeft het lezen van het arrest van het hof en het daaraan ten grondslag liggende vonnis van de rechtbank mij de wenkbrauwen doen fronsen. In de casus van de man en de vrouw is veel onduidelijkheid over de behandeling in het ziekenhuis. De administratie lijkt een rommeltje. Maar misschien was het gewoon de hectiek voortvloeiende uit de ernst van de situatie. En daarvan is dan afhankelijk wie het gehele vermogen van het onfortuinlijke echtpaar krijgt. Dat is mij te veel toeval. Daar moet de redelijkheid en billijkheid haar helende werking doen.

Dat de commoriëntenregeling is ontleend aan een verdrag, hoeft aan de toepassing van de derogerende werking van de redelijkheid en billijkheid niet af te doen. Het verdrag regelt hoe de volgorde van overlijden moet worden bepaald. De volgorde van overlijden heeft gevolgen voor de vraag wie de erfgenamen zijn in de zin van artikel 4:10 BW. Dit is een Nederlandse regeling die niet is onderworpen aan verdragsrecht, zodat hiervan met een beroep op de redelijkheid en billijkheid mag worden afgeweken.

\section{Conclusie}

Op 12 mei 2020 heeft hof Den Haag uitspraak gedaan in een treurige zaak. Op hun huwelijksreis komen man en vrouw kort na elkaar te overlijden. Vast staat dat de vrouw als eerste is overleden. De rechtbank past artikel 4:10 BW niet toe volgens de letter, maar bepaalt dat de nalatenschap van de man naar zijn familie gaat en de nalatenschap van de vrouw naar haar familie. De rechtbank doet dat onder toepassing van de derogerende wer- king van de redelijkheid en billijkheid. Het hof vernietigt het vonnis in hoger beroep.

Veel belang hechtte het hof aan de rechtszekerheid. Naar ik meen heb ik aangetoond dat de rechtszekerheid in erfrechtzaken niet snel in het geding is. De wet kent vele beschermingsmechanismen voor zowel erfgenamen en beweerdelijke erfgenamen als schuldeisers.

Ook de argumenten tegen toepassing van de derogerende werking van de redelijkheid en billijkheid acht ik niet doorslaggevend. Afgezien van de onduidelijkheid rond het overlijden van het echtpaar, is het naar mijn mening in strijd met de redelijkheid en billijkheid strikt aan te sluiten bij de overlijdensvolgorde als derden bij het overlijden zijn betrokken. Deze derden, artsen, politieambtenaren, brandweerlieden enzovoort, kunnen de volgorde van overlijden beïnvloeden. Dit mag geen gevolgen hebben voor de vraag wie erfgenaam is. Het hof miskent dit volledig. De rechtbank was wijzer.

Laten de verwikkelingen van het onfortuinlijke echtpaar ook een aanmoediging zijn voor het maken van een testament. Dan was deze procedure niet gevoerd. 